\title{
RECURRENCE WITHIN 24 HOURS OF UNPROVOKED SEIZURES
}

The incidence and risk factors of acute recurrence of unprovoked seizures within 24 hours of admission to an Emergency Department (ED) were analyzed by a retrospective chart review at Schneider Children's Hospital, New York. Children taking antiepileptic drugs (AED) were excluded. Of 117 patients analyzed, 69 (59.0\%) were admitted. Children more likely to be admitted were of younger age (mean, 3 years 8 months) than those discharged (mean age, 8 years), $\mathrm{P}<0.01$; they had multiple rather than single seizures before arrival at the $\mathrm{ED}(\mathrm{P}<0.001)$; and they had received AED in the ED $(\mathrm{P}<0.001)$. Children with symptomatic seizures were not admitted more frequently than those of idiopathic etiology. Fourteen (20\%) of admitted patients had one or more seizure recurrences within 24 hours. Multiple seizures before arrival at the ED was a significant risk factor for acute recurrence $(\mathrm{P}<0.05)$. EEGs were obtained in 59 (85.5\%) of 69 admissions; they were normal in 33 and abnormal in 26, epileptiform in 18. An abnormal EEG was not correlated with acute seizure recurrence within 24 hours. Treatment in the ED (lorazepam in 16 children, lorazepam and phenytoin in 4) did not lower the acute seizure recurrence rate. The authors recommend admission for observation of children presenting at the ED with an unprovoked seizure who are not on AED treatment. (Sogawa Y, Maytal J. Emergency department admission of children with unprovoked seizure: Recurrence within 24 hours. Pediatr Neurol August 2006;35:98-101). (Respond: Dr Sogawa, Montefiore Medical Center, Epilepsy Center, 111 East $210^{\text {th }}$ Street, Bronx, NY 10467).

COMMENT. Unprovoked seizures in children untreated with AED, especially patients with a history of prior seizure recurrence, require close observation and follow-up. The use of a short acting AED alone in the above center would explain the failure of ED treatment to lower the acute seizure recurrence rate. In a previous prospective study of 407 children with a first unprovoked seizure, followed for a mean of 6.3 years, seizures recurred in $42 \%$, one-half the recurrences within 6 months and almost $90 \%$ within 2 years. Risk factors for seizure recurrence included a remote symptomatic etiology, abnormal EEG, nocturnal seizure, prior febrile seizure, and Todd's paresis. A favorable prognosis $(21 \%$ recurrence risk after 5 years) was correlated with a cryptogenic etiology, a first seizure while awake, and normal EEG. (Shinnar S et al. Pediatrics 1996;98:216-225; Ped Neur Briefs Oct 1996). The control of seizures by AEDs and a favorable long-term remission are accompanied by heightened self-esteem, improved school achievement, and social acceptance by peers. An improved quality of life is justification for rational therapy, with precautions to avoid adverse side effects. (Shinnar S, Berg AT. Epilepsia 1996;37:701-708; Ped Neur Briefs Oct 1996).

\section{MUSICOGENIC SEIZURES AND TEMPORAL LOBE FOCI}

Medically intractable musicogenic epilepsy in 3 adults, with onset at age 5 years in 2 and 18 years in 1, was investigated with ictal magnetoencephalography, magnetic resonance spectroscopy, and presurgical intracranial EEG monitoring, at Vanderbilt University Medical Center, Nashville, TN. Seizures were precipitated by various forms of music, popular rhythms, church hymns, and by playing an electric keyboard. Auras consisted of a tune heard 
in the head, unpleasant abdominal sensation, and an odor. Seizures were localized to various temporal regions, right lateral, right mesial, and independently in both mesial temporal lobes. Two patients with unilateral ictal foci who underwent surgery are seizure free. (Tayah TF, Abou-Khalil B, Gilliam FG et al. Musicogenic seizures can arise from multiple temporal lobe foci: Intracranial EEG analyses of three patients. Epilepsia August 2006;47:1402-1406). (Reprints: Dr MJ Gallagher, Department of Neurology, Vanderbilt University Medical Center, 6140 Medical Research Building III, $46521^{\text {st }}$ Ave, South, Nashville, TN 37232 ).

COMMENT. Musicogenic epilepsy is a heterogeneous syndrome arising from various temporal lobe foci. Resective surgery should be considered for patients with unilateral ictal localization. The first reports of musicogenic epilepsy are usually ascribed to Macdonald Critchley (Brain 1937;60:13-27; cited in Penfield W, Jasper H. Epilepsy and the Functional Anatomy of the Brain, Boston, Little, Brown; 1954;p39), although earlier references, notably one involving Berlioz, are mentioned by Lennox WG. (In Epilepsy and Related Disorders, Boston, Little, Brown; 1960;pp361-365). Adults appear to be affected more frequently than children.

\section{MITOCHONDRIAL PROFILES AND THE ANTICONVULSANT EFFECT OF THE KETOGENIC DIET}

A study of the anticonvulsant effect of the ketogenic diet (KD) in adolescent rats, at Emory University and other centers, found that the hippocampus responds by inducing mitochondrial biogenesis, enhancing metabolic gene expression, and increasing energy reserves. The density of mitochondrial profiles in the dentate gyrus was increased by $46 \%$. An energy preservation hypothesis leading to alternative energy stores is proposed for the diet, especially important for the survival and function of GABAergic interneurons under stressful conditions. (Bough KJ, Wetherington J, Hassel B et al. Mitochondrial biogenesis in the anticonvulsant mechanism of the ketogenic diet. Ann Neurol August 2006;60:223-235). (Respond: Dr Bough, Food and Drug Administration, Center for Drug Evaluation and Research, MPN 1, Room 1345, 7520 Standish Place, Rockville, MD 20855).

COMMENT. These authors propose that chronic ketosis activates a genetic program that leads to mitochondrial biogenesis in the hippocampus, resulting in enhanced energy stores. Sustained ATP levels during stress allow membrane stabilization and elevation of the seizure threshold. Alternative mechanisms of action of the ketogenic diet previously proposed have included the anesthetic effects of ketone bodies, the associated acidosis, and changes in electrolytes. In clinical balance studies performed at the Mayo Clinic, where the diet was first introduced (Wilder RM. Mayo Clin Bull 1921;2:307), an anticonvulsant effect was unrelated to diuresis, independent of acidosis and ketosis, and was correlated with an increased urinary excretion and negative balance of sodium and potassium (Millichap JG, Jones JD. Epilepsia 1964;5:239-255). In animal studies, an anticonvulsant effect of a high fat, low carbohydrate diet was demonstrated in mice with a seizure threshold first lowered by water intoxication and hypoelectrolytemia; seizure susceptibility was not modified by a similar diet in normal animals (Millichap JG et al. Amer J Dis Child 1962;104:506; idem/ibidem 1964;107:593-604). 